\title{
Pengaruh Konsentrasi Resin Dan Suhu Pemanasawetan Terhadap Kekuatan Sobek Kain Kapas 100\% Pada Proses Penyempurnaan Anti Kusut
}

\author{
Tri Wardoyo Ds ${ }^{1)}$, Firdaus Ishmathuhom ${ }^{2)}$, Muhamad Taufik ${ }^{3)}$ \\ Jurusan Teknik Kimia, Fakultas Teknik, Universitas Islam Syekh-Yusuf, Jl. Maulana Yusuf No.10 \\ Tangerang Banten 15118, Indonesia \\ 1) triwardoyods@unis.ac.id \\ ${ }^{2)}$ firdausismathuhom@gmail.com \\ ${ }^{3)}$ muhamadtaufik306@gmail.com
}

\begin{abstract}
Abstrak. Penyempurnaan akhir kain dengan menggunakan resin akan meningkatkan kestabilan dimensi pada kain sehingga kain menjadi lebih kaku dan ketahanan kusut kain meningkat. Larutan resin akan masuk kedalam serat dan akan berpolimerisasi atau bereaksi dengan serat sehingga serat terlapisi oleh resin. Semakin banyak resin yang digunakan, maka akan semakin banyak resin yang berpolimerisasi dan kain akan semakin kaku serta ketahanan kusut kain semakin meningkat. Namun, semakin kaku kain maka kekuatan sobek kain akan semakin turun. Penurunan kekuatan sobek kain yang besar akan menyebabkan kekuatan sobek kain tidak sesuai dengan standar yang dipersyaratkan. Maka dalam penelitian ini jumlah atau konsentrasi resin yang digunakan divariasikan yaitu 5g/L, 10 $\mathrm{g} / \mathrm{L}, 25 \mathrm{~g} / \mathrm{L}$. Karena terjadi proses polimerisasi resin, maka reaksinya sangat dipengaruhi oleh proses suhu pemanasawetan. Suhu pemanasawetan divariasikan yaitu $140^{\circ} \mathrm{C}, 150^{\circ} \mathrm{C}, 160^{\circ} \mathrm{C}$. Hasil analisa menunjukkan bahwa anti kusut kain dengan kenaikkan konsentrasi resin berturut turut mengalami kenaikan dan berbanding terbalik dengan kekuatan sobek kainnya yang secara berturut-turut menurun. Sementara anti kusut kain dengan suhu pemanasawetan $140^{\circ} \mathrm{C}, 150^{\circ} \mathrm{C}, 160^{\circ} \mathrm{C}$ secara berturut-turut meningkat dan berbanding terbalik dengan kekuatan sobek kainnya yang secara berturut-turut menurun. Hasil konsentrasi resin yang optimal untuk kekuatan sobek kain pada $5 \mathrm{~g} / \mathrm{L}$ dengan pada suhu $140^{\circ} \mathrm{C}$.
\end{abstract}

Kata kunci : Anti Kusut, Kekuatan Sobek Kain, Resin, Suhu Pemanasawetan

Abstract. Finishing the fabric using resin will increase the dimensional stability of the fabric so that the fabric becomes stiffer and the creasing resistance of the fabric increases. The resin solution will enter the fiber and will polymerize or react with the fiber so that the fiber is coated by the resin. The more resins used, the more resins that polymerize and the fabric will be stiffer and the creasing resistance of the fabric will increase. However, the more rigid the fabric is, the more the fabric will tear. A decrease in fabric tear strength that will cause a large fabric tear strength does not meet the required standards. So in this study the amount or concentration of resin used varied, namely $5 \mathrm{~g} / \mathrm{L}$, $10 \mathrm{~g} / \mathrm{L}, 25 \mathrm{~g} / \mathrm{L}$. Due to the resin polymerization process, the reaction is greatly influenced by the temperature of the heating process. The heating temperature varies, ie $140^{\circ} \mathrm{C}, 150^{\circ} \mathrm{C}, 160^{\circ} \mathrm{C}$. The results of the analysis showed that the anti-creasing fabric with an increase in the concentration of resin had an increase and was inversely proportional to the strength of the fabric tearing which successively decreased. While anti-creasing fabric with heating temperature of $140^{\circ} \mathrm{C}, 150^{\circ} \mathrm{C}, 160^{\circ} \mathrm{C}$ respectively increases and is inversely proportional to the strength of the fabric tearing successively decreases. The optimal resin concentration results for the fabric tear strength at $5 \mathrm{~g} / \mathrm{L}$ with a temperature of $140^{\circ} \mathrm{C}$.

Keywords: Anti-Tangle, Fabric Tearing Strength, Resin, Heating Temperature 


\section{PENDAHULUAN}

Serat kapas mempunyai sifat mudah menyerap air, kekuatan daya cucinya cukup tinggi dan nyaman dipakai sehingga banyak dari perusahaan tekstil yang mempergunakan serat kapas sebagai bahan baku pembuatan kain. Namun kekurangan dari serat kapas yaitu mudah sekali kusut.

Perusahaan tekstil melakukan berbagai usaha untuk memperbaiki kekurangan tersebut, salah satu cara yang digunakan adalah dengan melakukan penyempurnaan serat kapas dengan menggunakan resin sintetik.Dampak dari proses tersebut stabilitas dimensi serat menjadi lebih stabil karena terlapisi resin dan ketahanan kusut serat menjadi lebih baik. Namun kekuatan sobek kain menurun.

Proses pemanasawetan dengan Resin Dimetiloldihidroksietilenaurea (DMDHEU) akan berpolimerisasi dan berikatan dengan serat atas bantuan katalis pada suhu tinggi. Katalis akan melepaskan asam sehingga serat terhidrolisa yang menyebabkan rantai karbon serat selulosa semakin pendek dan akhirnya menurunkan kekuatan sobek kain kapas.

Penurunan tersebut berkisar antara 30\%-50\%, sehingga tidak memenuhi standar ISO yang diterapkan perusahaan. Oleh karena latar belakang tersebut, dilakukan penelitian terhadap proses penyempurnaan anti kusut yang memfokuskan pada kekuatan sobek kain dengan faktor yang mempengaruhi, yaitu konsentrasi resin dan suhu pemanasawetan. Teknik pemanasawetan yang dipergunakan adalah teknik pemanasawetan kering.

Tujuan dari penelitian ini adalah untuk mengetahui apakah ada pengaruh konsentrasi resin, suhu pemanasawetan, dan interaksi antar konsentrasi resin dan suhu pemanasawetan terhadap kekuatan sobek kain kapas $100 \%$, serta mendapatkan konsentrasi optimum penggunaan resin dan suhu pemanasawetan pada proses penyempurnaan anti kusut.

Proses penyempurnaan secara kimia memberikan efek yang lebih permanen terhadap kain. sehingga penggunaan bahan tekstil akan lebih luas dan memliki nilai jual yang lebih tinggi.

Molekul serat kapas tersusun dari monomermonomer anhidroselulosa,yang terdiri dari bagian dengan rantai molekul yang teratur disebut kristalin dan bagian yang rantai molekulnya kurang teratur disebut amorf. Ketika ditekuk, kain akan mendapatkan gaya tekuk yang besar. Rantai-rantai dibagian kristalin akan dapat kembali ke kondisi semula karena berikatan kuat dengan rantai yang ada didekatnya, sementara bagian amorf rantainya akan terputus karena ikatannya kurang kuat dan bergeser relatif satu terhadap lainnya. Proses terjadinya kekusutan kain dapat dilihat pada gambar 1, sebagai berikut:

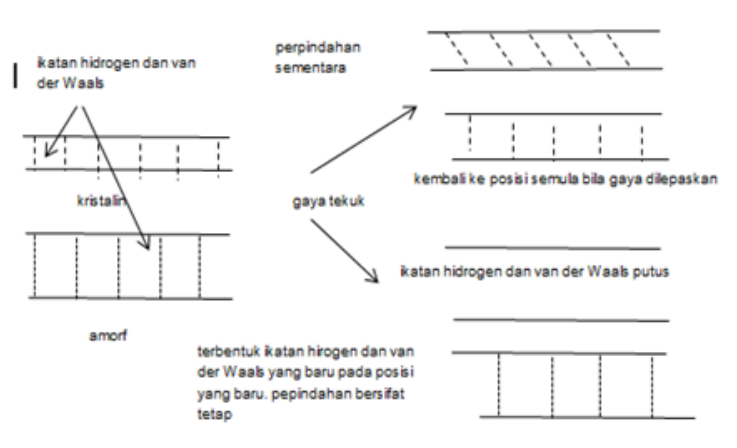

Gambar 1. Proses Terjadinya Kekusutan Kain

Resin merupakan senyawa organik yang kompleks dengan bobot molekul yang besar dan rantai karbon yang panjang. Penyempurnaan tahan kusut tidak digunakan dalam bentuk polimernya, melainkan dalam bentuk prakondensat hasil reaksi polimerisasi kondensasi yang memiliki ukuran cukup kecil. Untuk berpenetrasi masuk melalui pori-pori ke bagian amort dalam serat. Pada saat pemanasawetan prakondensat membentuk ikatan dengan rantai molekul serat dan menjadi bagian dari polimer serat, sedangkan prakondensat dari jenis selfcrosslinking membentuk polimer tiga-dimensi yang mengisi ruang antar molekul pada bagian amorf dan mencegah pergeseran relatif rantai molekul dengan cara menutup ruang geraknya (blocking).

Tahap proses penyempurnaan resin untuk tahan kusut adalah seperti berikut:

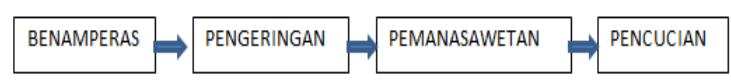

Gambar 2. Tahapan Proses Penyempurnaan

\section{Bahan dan Metode}

Metode yang digunakan adalah metode kualitatif eksperimen skala laboratorium dengan menggunakan analisis varians untuk percobaan 2 faktor dalam desain penelitian RAL (Rangkaian Acak Lengkap) 3x3 dengan 3 x pengulangan. Hubungan Klausalnya digambarkan sebagai berikut :

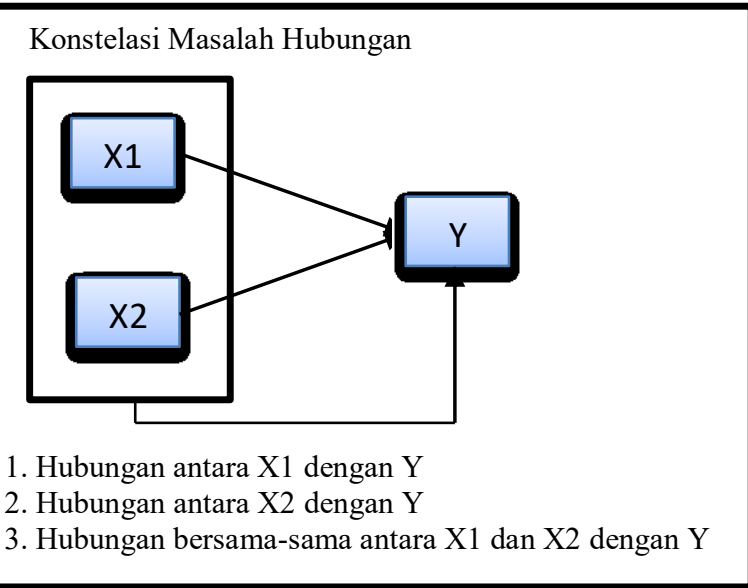


Gambar 3. Hubungan Klausal Variabel X Terhadap Y Percobaan dilakukan dilakukan di PT Argo Pantes Tbk. Adapun alat, bahan dan prosedur penelitian adlah sebagai ${ }^{\text {berikut }}$ :

\section{Bahan}

a. Kain kapas dengan konstruksi kain sebagai berikut :

Anyaman : Jeratan Kiri

Total per $\mathrm{cm}$ :

-Lusi : 39 helai

-Pakan : 30 helai

Ukuran : $50 \times 50 \mathrm{~cm}$

Berat : $25 \mathrm{~g}$

b. Resin Arkofix

c. Air

d. Pelemas, pengatur warna, katalis, OBA

\section{Peralatan}

a. Piala Gelas Plastik $500 \mathrm{~mL}$

b. Neraca Analitik

c. Mesin Pad Skala Laboratorium

d. Mesin Tenter Skala Laboratorium

e. Kertas $\mathrm{pH}$ Indikator

f. Alat Tearing Strength

g. Alat Crease O'meter

\section{Persiapan Bahan}

Sebelum proses penyempurnaan resin, kain terlebih dahulu melewati proses pretreatment, meliputi:
a. Pembakaran Bulu
b. Penghilangan Kanji
c. Pemasakan
d. Pengelantangan
e. Merserisasi

\section{Resep}
a. F/W Blue Rich $: 2 \mathrm{~mL} / \mathrm{L}$
b. F/W Violet FFBN : $19 \mathrm{~mL} / \mathrm{L}$
c. Eksafoam NFS : $2 \mathrm{~g} / \mathrm{L}$
d. Invadin PBN $: 2 \mathrm{~g} / \mathrm{L}$
e. Lecophor BMK : $2,7 \mathrm{~g} / \mathrm{L}$
f. Arkofix Net ID : $5 \mathrm{~g} / \mathrm{L} ; 15 \mathrm{~g} / \mathrm{L} ; 25 \mathrm{~g} / \mathrm{L}$
g. $\mathrm{MgCl}_{2}: 5 \mathrm{~g} / \mathrm{L}$
h. Megasoft WIN : $10 \mathrm{~g} / \mathrm{L}$
i. Velustrol PA ID : $30 \mathrm{~g} / \mathrm{L}$

\section{Pengujian}

a. Pembuatan larutan prakondensat

1) Menimbang semua zat-zat penyempurnaan.

2) Melarutkan semua zat menggunakan air sebanyak $500 \mathrm{~mL}$

b. Proses Penyempurnaan

1) Kain direndam dalam larutan prakondensat, kemudian dilewatkan ke padder dengan WPU 60\%-70\%
2) Kain dipanasawetkan dengan kondisi suhu $140^{\circ} \mathrm{C}, 150^{\circ} \mathrm{C}$ dan $160^{\circ} \mathrm{C}$ selama $4-6$ menit

3) Kain dicuci dengan air dan dikeringkan

4) Kain dievaluasi terhadap kekuatan sobek

\section{Teknik Pengumpulan Data}

Data hasil percobaan, kemudian dimasukkan kedalam tabel berikut :

Tabel 1. Variasi Konsentrasi resin dan Suhu

\begin{tabular}{cllll}
\hline \multirow{2}{*}{$\begin{array}{c}\text { Konsentrasi } \\
(\mathrm{g} / \mathrm{L})\end{array}$} & Arah & \multicolumn{3}{c}{ Suhu } \\
\cline { 2 - 4 } & & $140^{\circ} \mathrm{C}$ & $150^{\circ} \mathrm{C}$ & $160^{\circ} \mathrm{C}$ \\
\hline 5 & Lusi & & & \\
& Pakan & & \\
\hline 15 & Lusi & & \\
& Pakan & \\
\hline 25 & Lusi & \\
& Pakan & \\
\hline
\end{tabular}

\section{1) Teknik Analisa Data}

Data yang sudah didapatkan, kemudian diolah secara statistik dengan menghitung Jumlah Kuadrat, derajat bebas, KT, dan F Hitung sehingga didapatkan hasil menggunakan Metode ANOVA.

\section{2) Menghitung dB}

Derajat bebas total (dbt)

$$
d b t=(a x b x r)-1
$$

Derajat bebas perlakuan (dbt)

$$
d b p=(a x b-1)
$$

Derajat bebas faktor A (dba)

$$
d b a=a-1
$$

Derajat bebas faktor B (dbb)

$$
d b b=b-1
$$

Derajat bebas interaksi faktor A $\left(\mathrm{dba}^{*} \mathrm{~b}\right)$

$$
d b a^{*} b=(a-1)(b-1)
$$

Derajat bebas galat (dbg)

$$
d b g=d b t-d b p
$$

3) Menghitung Faktor Koreksi

$$
F K=\frac{\mathrm{Yij}^{2}}{a \times b \times r}
$$

\section{4) Menghitung Jumlah Kuadrat}

Jumlah Kuadrat Total (JKT)

$$
J K T=\sum\left(Y_{i j k}\right)^{2}-F K
$$

Jumlah Kuadrat Perlakuan

$$
J K P=\frac{\sum\left(\sum y_{j}\right)^{2}}{r}-F K
$$

Jumlah Kuadrat Faktor A (JKA)

$$
J K A=\frac{\sum\left(\sum y_{j i}\right)^{2}}{r_{b}}-F K
$$

Jumlah Kuadrat Faktor B (JKB)

$$
J K B=\frac{\sum\left(\sum y_{j}\right)^{2}}{r_{a}}-F K
$$

Jumlah Kuadrat Interaksi A*B (JKA*B)

$$
J K A^{*} B=J K P-J K A-J K B
$$




\begin{tabular}{|c|c|c|c|c|c|}
\hline \multirow[b]{2}{*}{ Faktor } & & \multicolumn{3}{|c|}{ Faktor Suhu (B) } & \multirow{2}{*}{$\begin{array}{l}\text { Rata- } \\
\text { rata A }\end{array}$} \\
\hline & & $140^{\circ} \mathrm{C}$ & $150^{\circ} \mathrm{C}$ & $160^{\circ} \mathrm{C}$ & \\
\hline \multirow{4}{*}{$\begin{array}{c}\text { Faktor } \\
\text { Konsentrasi } \\
\text { Resin (A) } \\
(\mathrm{g} / \mathrm{L})\end{array}$} & 5 & 680 & 640 & 600 & 640 \\
\hline & & & & & \\
\hline & 15 & 613,3 & 586,7 & 560 & 586,7 \\
\hline & 25 & 573,3 & 546,7 & 520 & 546,7 \\
\hline Rata-rata B & & 622,2 & 591,1 & 560 & - \\
\hline & $K G$ & $\begin{array}{l}\text { at Gal } \\
J K T-\end{array}$ & $\begin{array}{l}(\mathrm{JKG}) \\
K P\end{array}$ & & (13) \\
\hline
\end{tabular}

5) Menghitung Kuadrat Tengah

Kuadrat Tengah Perlakuan (KTP)

$$
K T P=\frac{J K P}{d b p}
$$

Kuadrat Tengah Faktor A (KTA)

$$
K T A=\frac{J K A}{d b a}
$$

Kuadrat Tengah Faktor B (KTB)

$$
K T B=\frac{J K B}{d b b}
$$

Kuadrat Tengah Interaksi Faktor AB $\left(\mathrm{KTA}^{*} \mathrm{~B}\right)$

$$
K T A^{*} B=\frac{J K A^{*} B}{d b a^{*} b}
$$

Kuadrat Tengah Galat (KTG)

$$
J K G=\frac{J K G}{d b g}
$$

6) Menghitung Frekuensi Hitung (F Hit)

$$
\begin{aligned}
& F_{\text {hitung } P}=\frac{K T P}{K T G} \\
& F_{\text {hitung } A}=\frac{K T A}{K T G} \\
& F_{\text {hitung } B}=\frac{K T B}{K T G} \\
& F_{\text {hitung } A_{B}^{*}}=\frac{K T A^{*} B}{K T G}
\end{aligned}
$$

\begin{tabular}{|c|c|c|c|c|c|}
\hline \multirow{2}{*}{ Faktor } & & \multicolumn{3}{|c|}{ Faktor Suhu (B) } & \multirow{2}{*}{$\begin{array}{l}\text { Rata- } \\
\text { rata } A\end{array}$} \\
\hline & & $140^{\circ} \mathrm{C}$ & $150^{\circ} \mathrm{C}$ & $160^{\circ} \mathrm{C}$ & \\
\hline \multirow{3}{*}{$\begin{array}{c}\text { Faktor } \\
\text { Konsentrasi } \\
\text { Resin }(\mathrm{A}) \\
(\mathrm{g} / \mathrm{L})\end{array}$} & 5 & 920 & 840 & 786,7 & 848,9 \\
\hline & 15 & 893,3 & 800 & 773,3 & 822,2 \\
\hline & 25 & 880 & 786,7 & 760 & 808,9 \\
\hline Rata-rata B & & 897,8 & 808,9 & 773,3 & - \\
\hline
\end{tabular}

\section{Hasil Dan Pembahasan}

Dari hasil penelitian, didapatkan data bantu dua arah rata-rata kekuatan sobek kain kearah lusi yang terdapat pada tabel 2, sebagai berikut :

Tabel 2. Tabel Bantu Dua Arah Rata-Rata Kekuatan Sobek Kain Kearah Lusi
Sedangkan untuk data bantu dua arah rata-rata kekuatan sobek kain kearah pakan dapat dilihat pada tabel 3, sebagai berikut:

Tabel 3. Tabel Bantu Dua Arah Rata-Rata Kekuatan Sobek

\section{Konsentrasi Resin} Kain Kearah Pakan

Hasil pengujian kekuatan sobek kain yang sudah dilakukan penyempurnaan resin anti kusut dengan memvariasikan konsentrasi resin yang dipakai secara berturut-turut yaitu $5 \mathrm{~g} / \mathrm{L}, 15 \mathrm{~g} / \mathrm{L}$ dan $25 \mathrm{~g} / \mathrm{L}$ terlihat pada gambar 4.

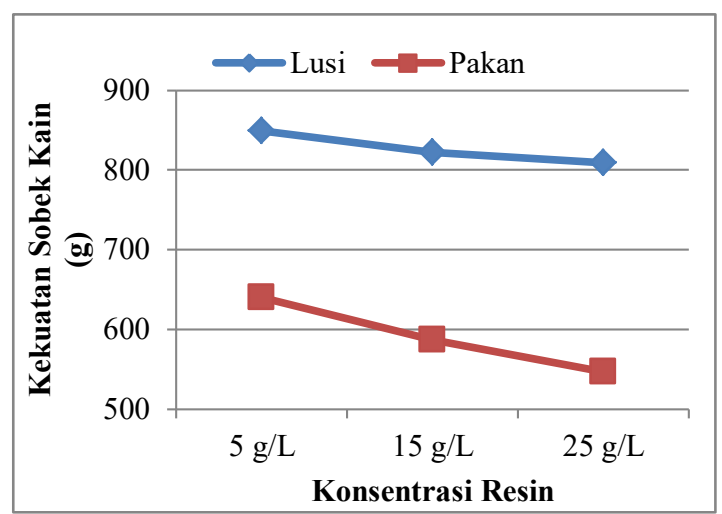

Gambar 4. Pengaruh Konsentrasi Resin Terhadap Kekuatan Sobek Kain

Dari gambar 4 terlihat bahwa semakin besar konsentrasi resin yang digunakan, maka kekuatan sobek kain semakin menurun baik arah lusi maupun kearah pakan kain.

Resin Arkofix merupakan resin DMDHEU, termasuk kedalam golongan resin reaktif yang dapat berikatan dengan seratpada suhu tinggi sehingga stabilitas dimensi serat menjadi lebih baik.Akibatnya ketahanan kusut kain meningkat, dan kain menjadi lebih kaku, dan lebih getas sehingga lebih mudah disobek atau kekuatan sobek kain menurun. Semakin banyak resin yang dipergunakan, maka semakin banyak yang berikatan atau berpolimerisasi didalam serat sehingga kekuatan kain akan semakin turun.

\section{Suhu Pemanasawetan}

Pengaruh dari suhu pemanasawetan terhadap kekuatan sobek kain dapat dilihat pada gambar 5 . 


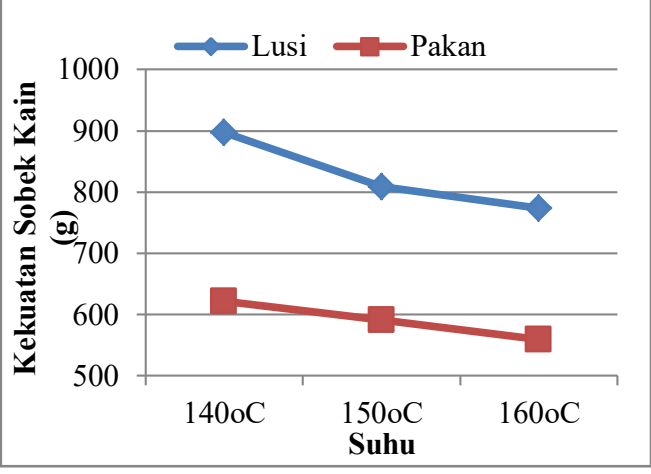

Gambar 5. Pengaruh Suhu Pemanasawetan terhadap Kekuatan Sobek Kain

Variasi Suhu yang digunakan yaitu $140^{\circ} \mathrm{C}, 150^{\circ} \mathrm{C}$ dan $160^{\circ} \mathrm{C}$. Gambar 5 menunjukkan bahwa dengan bertambahnya suhu, terdapat penurunan kekuatan sobek kain baik kearah pakan maupun kearah lusi. Semakin tinggi suhu yang digunakan, maka resin yang berpolimerisasi didalam serat akan semakin banyak.Sehingga meningkatkan anti kusut kain dan menunjukkan stabilitas dimensi serat menjadi lebih tinggi dan kain menjadi lebih kaku. Resin yang berpolimerisasi akan melapisi serat sehingga daya serap kain terhadap air berkurang. Hal ini membuat kain menjadi lebih getas dan mudah untuk sobek atau kekuatan sobek kain berkurang.

Sifat kapas yang tidak tahan terhadap suhu tinggi menyebabkan kapas menjadi lebih rapuh, dan kekuatan sobek kainnya pun akan rendah. Pada pemanasan suhu $120^{\circ} \mathrm{C}$ serat kapas tidak menunjukkan perubahan dan pada suhu $240^{\circ} \mathrm{C}$ kekuatan kapas hampir hilang.

Dengan teknik pemanasawetan kering dengan suhu berkisar $140^{\circ} \mathrm{C}-155^{\circ} \mathrm{C}$ dampak penurunan kekuatannya berkisar antara 30-50\%. Salah satu sifat kimia serat kapas yaitu dengan zat oksidator, penyinaran dalam keadaan lembab dan pemanasan pada suhu diatas $140^{\circ} \mathrm{C}$ dapat merusak kain karena terbentuk oksiselulosa sehingga kekuatan kain menjadi turun. Reaksi oksiselulosa adalah sebagai berikut :

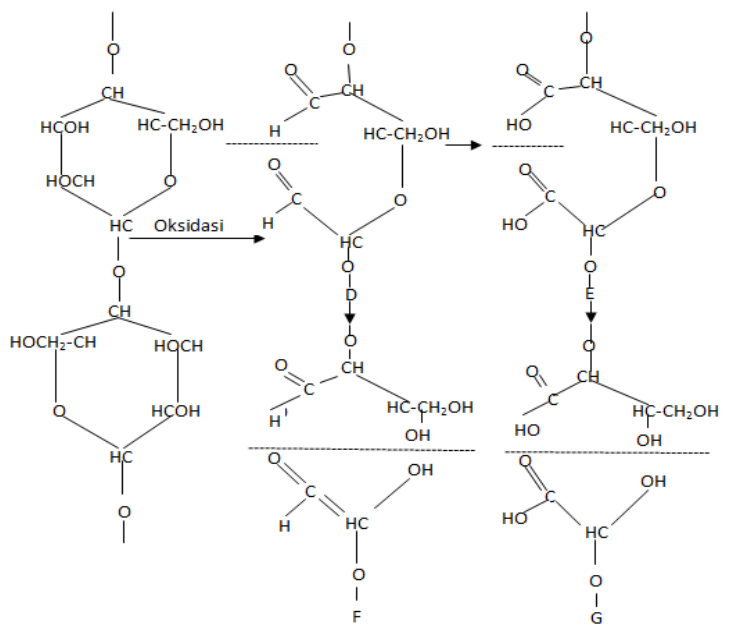

\section{Gambar 6. Reaksi Oksiselulosa}

Reaksi oksiselulosa dapat terjadi dalam beberapa tingkatan. Pada oksidasi sederhana misalnya oleh $\mathrm{NaOCl}$ dalam suasana asam tidak terjadi pemutusan tetapi hanya terjadi pembukaan cincin glukosa seperti jenis D. Pengerjaan lebih lanjut dengan alkali akan menyebabkan pemutusan rantai molekul yang menyebabkan kekuatan tarik turun dan memberikan hasil jenis $F$.

Oksiselulosa jenis $\mathrm{D}$ dan $\mathrm{F}$ mempunyai daya reduksi karena mempunyai gugus aldehid. Bila pengerjaan alkali ini berhubungan dengan udara, maka oksidasi memberikan hasil jenis $G$ yang mempunyai gugus - $\mathrm{COOH}$ - (karboksilat). Pada pengerjaan alkali secara normal, dengan adanya udara umumnya terjadi campuran sedikit jenis $\mathrm{G}$ dan $\mathrm{F}$.

Pada Proses polimerisasi resin berlangsung pada suhu tinggi, katalis yang dipergunakan akan mengeluarkan asam dan dapat terjadi reaksi hidroselulosa yang menyebabkan putusnya rantai karbon sehingga menjadi lebih pendek dan menurunkan kekuatan sobek kain. Reaksi hidroselulosa adalah sebagai berikut :
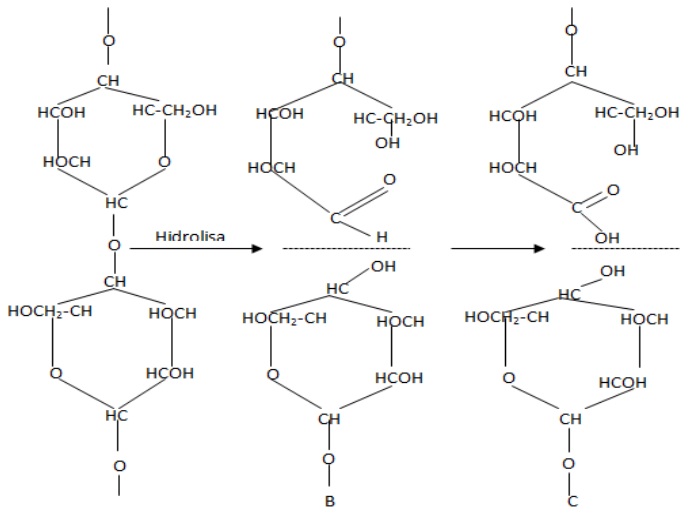

Gambar 7. Reaksi Hidroselulosa

\section{Anti Kusut Kain}

Hasil pengecekan anti kusut kain dilihat melalui derajat pemulihannya (Crease Recovery) dapat dilihat pada tabel 4 dan 5 .

Tabel 4. Crease Recovery Arah Lusi

\begin{tabular}{cccc}
\hline \multirow{2}{*}{$\begin{array}{c}\text { Faktor } \\
\text { Konsentrasi } \\
\text { Resin (A) }\end{array}$} & \multicolumn{3}{c}{ Faktor Suhu (B) } \\
\cline { 2 - 4 } & $140^{\circ} \mathrm{C}$ & $150^{\circ} \mathrm{C}$ & $160^{\circ} \mathrm{C}$ \\
\hline $5 \mathrm{~g} / \mathrm{L}$ & 104,5 & 105 & 111 \\
\hline $15 \mathrm{~g} / \mathrm{L}$ & 118 & 118,5 & 129 \\
\hline
\end{tabular}




\begin{tabular}{llll}
\hline $25 \mathrm{~g} / \mathrm{L}$ & 130 & 131 & 138 \\
\hline
\end{tabular}

Tabel 5. Crease Recovery arah Pakan

\begin{tabular}{cccc}
\hline \multirow{2}{*}{$\begin{array}{c}\text { Faktor } \\
\text { Konsentrasi } \\
\text { Resin (A) }\end{array}$} & \multicolumn{3}{c}{ Faktor Suhu (B) } \\
\cline { 2 - 4 } & $140^{\circ} \mathrm{C}$ & $150^{\circ} \mathrm{C}$ & $160^{\circ} \mathrm{C}$ \\
\hline $5 \mathrm{~g} / \mathrm{L}$ & 115 & 115,9 & 118,5 \\
\hline $15 \mathrm{~g} / \mathrm{L}$ & 116 & 120 & 120,5 \\
\hline $25 \mathrm{~g} / \mathrm{L}$ & 120 & 126 & 139
\end{tabular}

Dari tabel diatas, baik kearah lusi maupun pakan, semakin tinggi konsentrasi resin yang digunakan, derajat pemulihan kain semakin tinggi, maka ketahanan kusut kain akan semakin baik. Begitu pula dengan suhu, semakin tinggi suhu yang digunakan, maka semakin banyak resin yang berpolimerisasi sehingga ketahanan kusut kain akan semakin baik.

\section{Kesimpulan}

1. Konsentrasi resin berpengaruh terhadap kekuatan sobek kain kapas $100 \%$ pada proses penyempurnaan anti kusut.

2. Suhu pemanasawetan berpengaruh terhadap kekuatan sobek kain kapas $100 \%$ pada proses penyempurnaan anti kusut.

3. Interaksi Konsentrasi resin dan suhu pemanasawetan tidak berpengaruh nyata terhadap kekuatan sobek kain.

4. Kondisi optimum untuk mendapatkan kekuatan sobek kain yang optimum yaitu dengan konsentrasi resin $5 \mathrm{~g} / \mathrm{L}$ pada suhu $140^{\circ} \mathrm{C}$ dengan WPU $60 \%-70 \%$.

5. Semakin tinggi konsentrasi resin dan suhu pemanasawetan yang digunakan ketahanan kusut kain semakin bertambah, tetapi kekuatan sobek kain berkurang.

\section{Daftar Pustaka}

Hartanto, N. Sugiarto dan Watanabe Shingeru. (1993). Teknologi Tekstil. Jakarta : PT. Pradyana Paramita.

Henrodyantopo S dkk. (1999). Teknologi Penyempurnaan. Bandung : STT Tekstil.

Horrocks and Anand. (2000). Handbook of Technical Textiles. Woodhead Publishing Limited : Cambridge England.
Jumaeri, BK. Teks. (1974). Textile Design. Bandung : Institut Teknologi Tekstil.

S. Noerati, S. Teks. MT. (2013). Teknologi Tekstil. Bandung : STT Tekstil.

Saville B P. (1999). Physical Testing of Textiles. Woodhead Publishing Limited : Cambridge England.

Sigit Supardi, Ir. Drs. MM. (1998). Serat - Serat Tekstil. Tangerang : Universitas Islam Syekh Yusuf.

Taylor A. Marjorie. (1990). Technology of textile Properties. Forbes Publications Limited. 